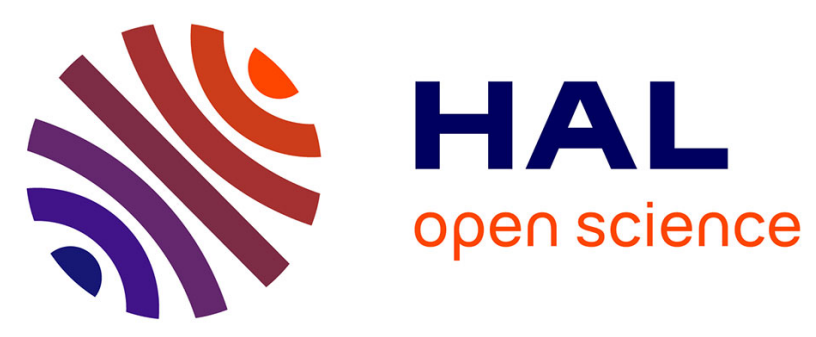

\title{
Rapid Natural-Abundance 2D 13 C- 13 C Correlation Spectroscopy Using Dynamic Nuclear Polarization Enhanced Solid-State NMR and Matrix-Free Sample Preparation
}

Hiroki Takahashi, Daniel Lee, Lionel Dubois, Michel Bardet, Sabine Hediger, Gaël De paëpe

\section{To cite this version:}

Hiroki Takahashi, Daniel Lee, Lionel Dubois, Michel Bardet, Sabine Hediger, et al.. Rapid NaturalAbundance 2D 13 C- 13 C Correlation Spectroscopy Using Dynamic Nuclear Polarization Enhanced Solid-State NMR and Matrix-Free Sample Preparation. Angewandte Chemie, 2012, 124 (47), pp.11936-11939. 10.1002/anie.201206102 . hal-02043242

\section{HAL Id: hal-02043242 \\ https://hal.science/hal-02043242}

Submitted on 29 Sep 2021

HAL is a multi-disciplinary open access archive for the deposit and dissemination of scientific research documents, whether they are published or not. The documents may come from teaching and research institutions in France or abroad, or from public or private research centers.
L'archive ouverte pluridisciplinaire $\mathbf{H A L}$, est destinée au dépôt et à la diffusion de documents scientifiques de niveau recherche, publiés ou non, émanant des établissements d'enseignement et de recherche français ou étrangers, des laboratoires publics ou privés. 


\title{
20 Minute Natural Abundance $2 \mathrm{D}^{13} \mathrm{C}-{ }^{13} \mathrm{C}$ Correlation Spectroscopy Using DNP-Enhanced Solid-State NMR and Matrix-Free Sample Preparation**
}

\author{
Hiroki Takahashi, Daniel Lee, Lionel Dubois, Michel Bardet, Sabine Hediger, Gaël De Paëpe*
}

Solid-state nuclear magnetic resonance (SSNMR) has been extensively used to characterize molecular structures at atomic scales. ${ }^{[1]}$ Concerning biomolecular applications, structural studies are commonly performed on ${ }^{13} \mathrm{C}$ and/or ${ }^{15} \mathrm{~N}$ enriched samples in order to compensate for their low natural abundance $\left(1.11 \%\right.$ for ${ }^{13} \mathrm{C}$ and $0.37 \%$ for $\left.{ }^{15} \mathrm{~N}\right)$. However, this strategy is mainly restricted to biomolecules that can be easily isotopically enriched and has proven difficult to expand to other types of systems.

To date, only a few examples of natural abundance (NA) $2 \mathrm{D}{ }^{13} \mathrm{C}-$ ${ }^{13} \mathrm{C}$ correlation experiments in solids have been reported using pulse sequences that rely on through-bond polarization transfer. ${ }^{[2]}$ This type of experiment provides one-bond connections and is limited to small crystalline molecules since it already requires 2 to 10 days of experimental time. Due to the low abundance of ${ }^{13} \mathrm{C}$ nuclei, crosspeak intensities are about 4 orders of magnitude smaller for experiments performed on NA systems compared to their labeled equivalents.

Recently, dynamic nuclear polarization (DNP) performed with a high-power high-frequency microwave source (gyrotron), a low temperature (LT) magic-angle spinning (MAS) probe and a suitable polarizing agent has emerged as an appropriate answer to the sensitivity limitation of SSNMR even at high magnetic fields. ${ }^{[3-5]}$ This work by Griffin and co-workers has triggered a strong interest in the science community and high-field MAS-DNP has been used on many different types of systems ranging from biological systems ${ }^{[6-8]}$ to materials. ${ }^{[9-11]}$ Here we will show that the sensitivity enhancement obtained with DNP can be significant enough to record $2 \mathrm{D}{ }^{13} \mathrm{C}-{ }^{13} \mathrm{C}$ NMR correlation spectra on NA microcrystalline solids in 20 minutes, ${ }^{[12]}$ i.e. within an experimental time comparable to experiments routinely performed on isotopically labeled systems.

The relevance of performing DNP experiments has so far mainly been judged by comparing the signal-to-noise ratio $(\mathrm{S} / \mathrm{N})$ with and without microwave $(\mu \mathrm{w})$ irradiation. This 'DNP enhancement' (EDNP) has shown factors of up to 200 at $9.4 \mathrm{~T}$ and $100 \mathrm{~K},{ }^{[5,13]}$ but in most applications, a factor of 10 to 20 is obtained. However, we demonstrate here that the effective sensitivity gain in DNP experiments cannot be simply evaluated by measuring $\varepsilon_{\mathrm{DNP}}$. Instead,

[*] Dr. H. Takahashi, Dr. D. Lee, Dr L. Dubois, Dr. M. Bardet, Dr. S. Hediger, Dr. G. De Paëpe

Laboratoire de Chimie Inorganique et Biologique, UMR-E3 CEA/UJF \& CNRS, Institut Nanosciences et Cryogénie (CEA/DSM), 38054 Grenoble

E-mail: gael.depaepe@cea.fr

[**] This work was supported by the ANR (ANR08-CEXC-00301 and ANR-08-BLAN-0306-02) and funding from the RTB. G.D.P. was supported by EU Marie Curie (PIEF-GA- 2009237646) for part of the work. D.L. was supported by CEAEUROTALENTS (PCOFUND-GA-2008-228664). Dr. M. Giffard is acknowledged for the synthesis of the TOTAPOL radical.

Supporting information for this article is available on the WWW under http://www.angewandte.org or from the author.((Please delete if not appropriate)) we propose to use the Absolute Sensitivity Ratio (ASR) to evaluate the relevance of DNP by comparing the $\mathrm{S} / \mathrm{N}$ per unit time obtained under optimized DNP conditions with the one obtained under standard NMR conditions (potentially using larger sample volumes, higher magnetic fields, etc.). Previously, Rossini et al. and Vitzthum et al. introduced an overall sensitivity factor ${ }^{[14]}$ and a global DNP factor ${ }^{[15]}$ respectively, which take into account some of the important parameters. These factors are reduced forms of the ASR and are discussed in more detail in the Supporting Information (SI) Sec. 4.

One of the main differences between conventional and DNPenhanced SSNMR experiments is the effective sample volume. For DNP experiments, samples of interest are usually dissolved ${ }^{[3,5]}$ or suspended ${ }^{[7,8]}$ in glassy chemical matrices in order to achieve uniform radical distribution which significantly reduces the effective amount of sample (e.g. $45 \mu \mathrm{L}$ of $0.1 \mathrm{M}$ glycine solution contains $0.34 \mathrm{mg}$ of glycine). Impregnation of DNP matrices into porous materials reduces this sample volume-reduction problem. ${ }^{[9]}$ Another approach was reported using a solvent-free method that utilizes a spin-labeling technique where the biradical TOTAPOL ${ }^{[16]}$ is covalently attached to a peptide. Enhancement factors of up to 4 were measured on a decapeptide. ${ }^{[15]}$ The use of solvents also causes spectral linebroadening due to the conformational distribution in frozen solutions. ${ }^{[17]}$

In order to optimize the sample volume and spectral resolution for MAS-DNP experiments, we developed a new sample preparation protocol based on a matrix-free (MF) approach where the polarizing agent is uniformly distributed around the microcrystals. This method maximizes the effective quantity of material observed and preserves its potential crystallinity, which then leads to narrower spectral lines at LT. This approach is demonstrated on a sample of microcrystalline cellulose using the TOTAPOL polarizing agent.

In Fig. 1, we compare 1D ${ }^{13} \mathrm{C}$ CPMAS spectra of NA microcrystalline cellulose (a-c) and $2{ }^{13} \mathrm{C}$ glycine (d-f). For DNP experiments, the cellulose sample was prepared with the MF approach, while the standard 'frozen-solution' preparation method was used for the glycine sample. Comparing the spectra with $\mu \mathrm{w}$-on and $\mu$ w-off, a similar DNP enhancement of 20 is obtained on both cellulose and glycine. However, when the DNP experiment is compared to the conventional NMR experiment at room temperature (RT) on powders, the ASR on glycine (0.021) is more than 3 orders of magnitude smaller than on cellulose (47). Notably, the S/N of the cellulose C2 site (the biggest peak) using DNP reaches 747 for a recycle delay of $13 \mathrm{~s}$ ( 5 times $T_{1}$ ) and 4 scans whereas it was 15 for the same number of scans with conventional NMR at RT (recycle delay of $11.5 \mathrm{~s}$ ).

The line-widths of the cellulose sample remain almost unchanged because it keeps its crystalline structure with the MF approach. On the other hand, the glycine peak is strongly broadened at lowtemperature, as the dissolved molecule is frozen in many different conformations.

Furthermore, the strong solvent peaks present in the frozensolution spectrum of glycine (Fig. 1f) do not appear in the case of MF-cellulose (Fig. 1c). This is because the MF approach does not 
require the use of a cryo-protectant (glycerol, DMSO, etc.) in order to form glassy matrices at LT and uniformly distribute the polarizing agent. This is very important for NA experiments because signals of interest are often buried under large solvent peaks.

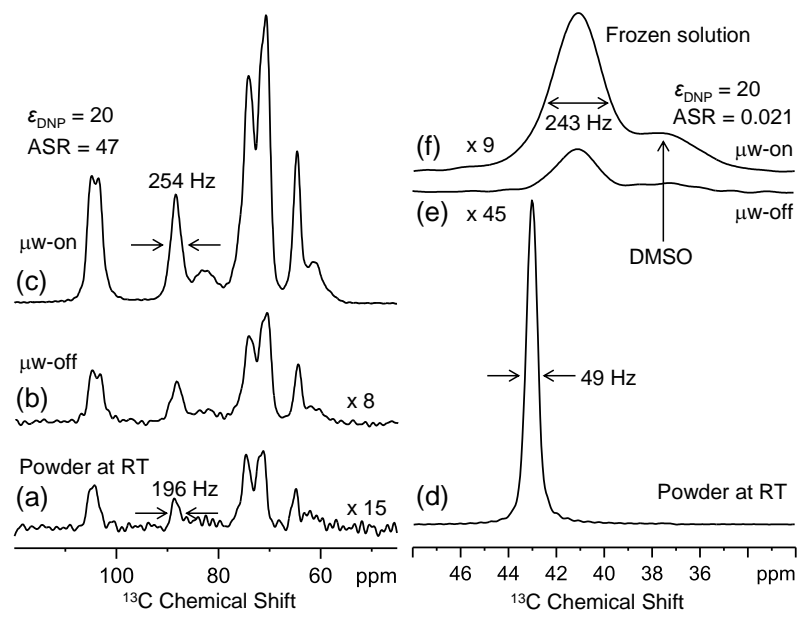

Figure 1. ${ }^{13} \mathrm{C}$-CPMAS spectra of NA microcrystalline cellulose (a-c) and $2-{ }^{13} \mathrm{C}$ glycine $(\mathrm{d}-\mathrm{f})$ recorded on a dried powder for conventional NMR experiments at RT $(a, d)$, a MF sample $(b, c)$ or a frozen solution (e, f) for DNP experiments at $105 \mathrm{~K}$ with $\mu \mathrm{w}$-off $(b, e)$ and $\mu \mathrm{w}$ on (c, f). The MAS frequency was $8 \mathrm{kHz}$ for all experiments. A DNP enhancement factor, $\varepsilon_{\mathrm{DNP}}$, of 20 was observed with a zirconium rotor although it is $30 \%$ less efficient compared to a sapphire rotor according to DNP experiments on ${ }^{13} \mathrm{C}$ urea (data not shown).

The substantial effective enhancement obtained on the MF NA cellulose allowed us to acquire a DNP-enhanced 2D double-quantum single-quantum (DQ-SQ) ${ }^{13} \mathrm{C}$ homonuclear dipolar correlation experiment. The $2 \mathrm{D}$ spectrum, obtained in only 20 minutes, is shown in Fig. 2a. All one-bond correlations are observed with good resolution and sensitivity using the POST-C $7^{[18]}$ recoupling sequence with a total mixing time of $1 \mathrm{~ms}$. In this case, the 20 minute experimental time is not limited by sensitivity but rather by the number of repetitions required to complete the phase cycling for DQ selection, the number of points necessary in the indirect dimension for sufficient resolution and the probe duty cycle. An experiment on a fully ${ }^{13} \mathrm{C}$-labeled system would require the same experimental duration.

By increasing the recoupling mixing time to $3.5 \mathrm{~ms}$, we were able to obtain in only 2 hours a spectrum (see Fig. 2b) containing all twobond correlations in NA cellulose $(\mathrm{C} 1-\mathrm{C} 3$, inter-unit $\mathrm{C} 1-\mathrm{C} 4, \mathrm{C} 1-\mathrm{C}$, $\mathrm{C} 2-\mathrm{C} 4, \mathrm{C} 3-\mathrm{C} 5$, and $\mathrm{C} 4-\mathrm{C} 6$ ). Since dipolar truncation is negligible for ${ }^{13} \mathrm{C}-{ }^{13} \mathrm{C}$ polarization transfer in $\mathrm{NA}$ systems, long range correlations are easier to measure than on fully ${ }^{13} \mathrm{C}$-labeled systems. Furthermore, in samples at $1 \%$ natural abundance, no relayed mechanism is involved in two-bond polarization transfers. This will enable the performance of long-range distance measurements with high accuracy. A DNP-enhanced 2D SQ-SQ ${ }^{13} \mathrm{C}$ homonuclear dipolar correlation experiment using $\mathrm{DARR}^{[19]}$ recoupling was also performed and is shown in SI Sec. 3.

Finally, we would like to discuss the essential concept of sensitivity enhancement in the context of DNP-enhanced NMR experiments. In order to evaluate the true sensitivity gain of performing DNP experiments, we have introduced above the experimental quality factor dubbed ASR. All the different contributions to the effective enhancement have to be considered to rationalize the measured ASR. We separate them into eight factors (see also SI Sec. 4):

1) EDNP: the standard DNP enhancement factor ( $\mu \mathrm{w}$-on/-off).

2) $\varepsilon_{T}$ : the gain obtained at LT, whose origin is twofold: the increase of magnetization due to the Boltzmann distribution and the reduction of thermal noise at LT.

3) $\eta_{\mathrm{T} 1}$ takes into account the different repetition times that can be used in the two experiments. It depends on the longitudinal relaxation time constant $T_{1}$ for the RT NMR experiment $\left(T_{1, \mathrm{RT}}\right)$ and on the DNP build-up time constant ( $\tau_{\mathrm{DNP}}$ ) for the DNP experiment. The square root of their ratio accounts for the $\mathrm{S} / \mathrm{N}$ per unit time: $\eta_{\mathrm{T} 1}=\left(T_{1, \mathrm{RT}} / \tau_{\mathrm{DNP}}\right)^{1 / 2}$.

4) $\chi$ bleach: the factor accounting for signal 'bleaching' ${ }^{[14,15]}$ caused by paramagnetic effects resulting from the presence of the radical in the DNP sample.

5) $\chi_{\mathrm{LW}}$ the ratio of the line-widths.

6) $\chi_{\text {weight }}$ the ratio of the effective sample weights taking into account the amount of material of interest in both experiments.

7) $\chi_{\text {seq }}$ the ratio of the effective magnetization after decays during the pulse sequence, i.e. mixing times, cross-polarization (CP) contact times, etc.

8) $\chi_{\text {ex }}$ the enhancement/reduction factor caused by extra effects if applicable (e.g. when using a different probe, magnetic field, etc.). The effective DNP enhancement factor, or ASR, can be expressed as the product of the different contributions:

$$
\mathrm{ASR}=\varepsilon_{\mathrm{DNP}} \cdot \varepsilon_{\mathrm{T}} \cdot \eta_{\mathrm{T} 1} \cdot \chi_{\text {bleach }} \cdot \chi_{\mathrm{LW}} \cdot \chi_{\text {weight }} \cdot \chi_{\text {seq }} \cdot \chi_{\mathrm{ex}}
$$
In most cases, both $\varepsilon \mathrm{DNP}$ and $\varepsilon_{\mathrm{T}}$ lead to sensitivity enhancement ( $\varepsilon \mathrm{DNP}$, $\left.\varepsilon_{\mathrm{T}}>1\right)$ and $\chi$ bleach, $\chi \mathrm{Lw}, \chi_{\text {weight, }} \chi_{\text {seq }}$ and $\chi_{\text {ex }}$, to sensitivity reduction (factors $<1$ ). Rigid samples without mobile/rotating groups, such as a methyl group, exhibit long $T_{1}$ times at RT that can be shortened by the addition of the polarizing agents. This then contributes positively to the ASR since $\eta_{\mathrm{T} 1} \gg 1$.

The eight different factors contributing to the ASR were measured for glycine and cellulose, and are summarized in Table 1. Large sensitivity reductions are observed on glycine in a frozen solution due to limited sample amount and line-broadening. These factors are minimized in the MF-cellulose. The microcrystalline structure is kept almost unchanged leading to $\chi_{\mathrm{LW}} \sim 0.77$. Since the sample is not dissolved in a matrix, the same sample amount can be used for DNP experiments as for conventional NMR experiments. In the case of the MF-cellulose, a factor $\chi_{\text {weight }}>1$ could even be obtained by moisturizing the sample for the DNP experiment (see SI Sec. 1). Using Eq. (1), ASRs of 0.020 and 47 are estimated for the glycine and cellulose samples, respectively. These are in excellent agreement with the experimental values $(0.021$ for glycine and 47 for cellulose). This clearly demonstrates that the ASR can be fully rationalized by the different contributions presented here.

In this work, we have introduced a new approach to record efficient multidimensional SSNMR correlation experiments on NA microcrystalline samples. Notably, we introduced a matrix-free sample preparation protocol that allows reaching excellent absolute sensitivity and the acquisition of 2D correlation spectra in a time equivalent to that needed for isotopically labeled systems. Thus, a 2D dipolar correlation experiment recorded in only 20 minutes has been presented on a MF NA cellulose sample. This method applied to NA correlation experiments also allows the detection of long distance transfer thanks to the lack of dipolar truncation. This sample preparation method can be further applied to labeled systems, opening up a new world of 4D (or higher dimensional) SSNMR experiments designed to improve resolution in complex systems. 

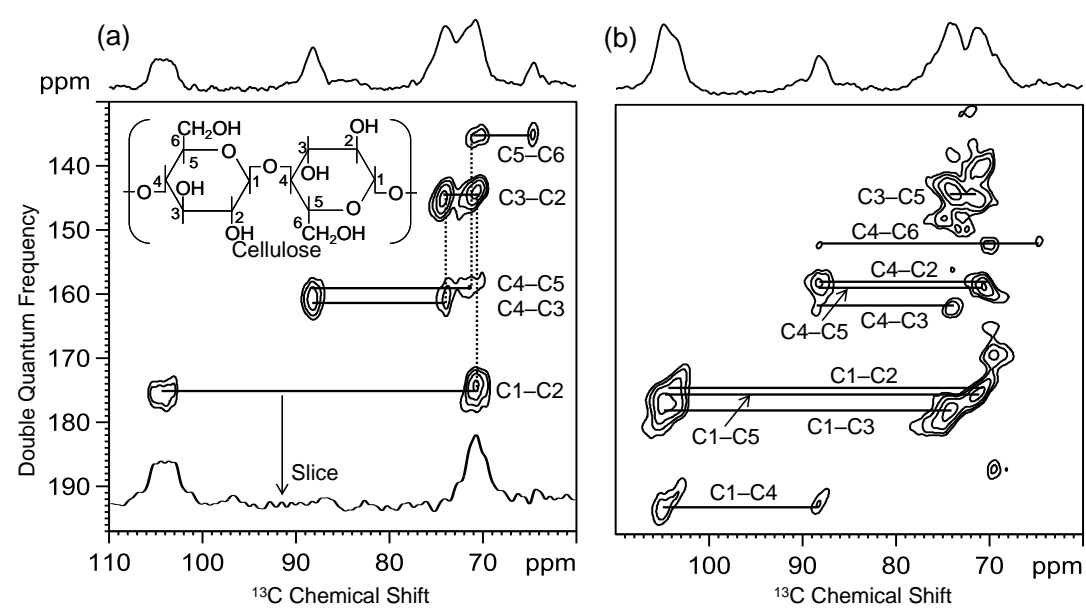

Figure 2. DNP-enhanced 2D DQ-SQ ${ }^{13} \mathrm{C}-{ }^{13} \mathrm{C}$ POST-C7 dipolar correlation spectra of MF NA microcrystalline cellulose recorded at $105 \mathrm{~K}$. MAS frequency and the number of scans are $8 \mathrm{kHz}$ and 16, respectively. a) The spectrum is obtained in 20 minutes with a recycle delay of $0.9 \mathrm{~s}, 1.4$ ms evolution time and $1 \mathrm{~ms}$ POST-C7 mixing. b) The experimental time is 2 hours with a recycle delay of $3.4 \mathrm{~s}, 2.3$ ms evolution time and 3.5 ms of POST-C7 mixing. Projections are shown on top.

Table 1. Summary of enhancement/reduction factors. ${ }^{[a]}$

\begin{tabular}{ccccccccc}
\hline & $\begin{array}{c}\mathrm{ASR}^{\mathrm{m}} \\
{\left[{ }^{\mathrm{b}]}\right.}\end{array}$ & $\varepsilon_{\mathrm{DNP}}$ & $\eta_{\mathrm{T} 1}$ & $\chi_{\text {bleach }}$ & $\chi\llcorner\mathrm{W}$ & $\chi_{\text {weight }}$ & $\begin{array}{c}\chi_{\text {seq }} \\
{[\mathrm{c}]}\end{array}$ & $\begin{array}{c}\mathrm{ASR}^{\mathrm{e}} \\
{[\mathrm{d}]}\end{array}$ \\
\hline Glycine & 0.021 & 20 & 0.38 & 0.60 & 0.20 & 0.0064 & 0.97 & 0.020 \\
Cellulose & 47 & 20 & 0.94 & 0.60 & 0.77 & 1.5 & 1.0 & 47 \\
\hline
\end{tabular}

[a] Taking into account the inefficient and incomplete probe circuit cooling, $\varepsilon_{\top}$ was estimated to $3.6 \pm 0.9$ since the gain is at maximum $(285 \mathrm{~K} / 105 \mathrm{~K})^{3 / 2}=4.5$ (i.e. the entire circuit is cooled down to $105 \mathrm{~K}$ ) and at minimum $(285 \mathrm{~K} / 105 \mathrm{~K})=2.7$ (i.e. the circuit is not cooled at all and considered at $285 \mathrm{~K}$ ). [b] Experimentally measured ASR. [c] Comparison of spin-lock decays during the CP period of $1 \mathrm{~ms}$. [d] Estimated ASR using Eq. (1). Further details in SI Sec. 4.

\section{Experimental Section}

Sample preparation: Biradical TOTAPOL was synthesized according to the literature. ${ }^{[16]} \mathrm{NA}$ microcrystalline cellulose (crystal size of $20 \mu \mathrm{m}$ ) and $2-^{13} \mathrm{C}$ glycine powder were purchased from Sigma-Aldrich. For conventional NMR experiments, cellulose was used without further treatment and fully packed in a rotor. For DNP experiments, $105 \mathrm{mg}$ of cellulose was suspended in $1.5 \mathrm{~mL}$ of $3 \mathrm{mM}$ TOTAPOL solution $\left(\mathrm{D}_{2} \mathrm{O}\right)$ and dried in a desiccator under vacuum. During this process, a fraction of TOTAPOL molecules are bound to the cellulose surface. The obtained sample was fully packed in a rotor with $2 \mu \mathrm{L}$ of $\mathrm{D}_{2} \mathrm{O}$ to moisturize the sample (See SI Sec. 1). Glycine powder was dissolved in $\mathrm{d}_{6}-\mathrm{DMSO} / \mathrm{D}_{2} \mathrm{O} / \mathrm{H}_{2} \mathrm{O}(6: 3: 1 \mathrm{v} / \mathrm{v} / \mathrm{v})$ and TOTAPOL was added to obtain a $0.1 \mathrm{M}$ glycine / $20 \mathrm{mM}$ TOTAPOL solution for DNP experiments. Glycine powder $(53 \mathrm{mg})$ and the above solution $(45 \mu \mathrm{L})$ were fully packed into a rotor.

NMR experiments: All experiments were performed on a Bruker AVANCE $^{\text {TM }}$ III $400 \mathrm{MHz}$ wide-bore NMR system equipped with a 263 $\mathrm{GHz}$ gyrotron, a transmission line and a $\mathrm{LT}(\sim 100 \mathrm{~K})$ triple resonance $3.2 \mathrm{~mm}$ MAS probe. ${ }^{[5]}$ Details are described in SI Sec. 2.

Received: ((will be filled in by the editorial staff)) Published online on ((will be filled in by the editorial staff))

Keywords: absolute sensitivity ratio - Analytical Methods - dynamic nuclear polarization · NMR spectroscopy · solvent-free sample
[1] D. D. Laws, H. M. L. Bitter, A. Jerschow, Angew. Chem. Int. Ed. 2002, 41, 3096-3129.

[2] a) H. Kono, T. Erata, M. Takai, Macromolecules 2003, 36, 51315138; b) R. A. Olsen, J. Struppe, D. W. Elliott, R. J. Thomas, L. J. Mueller, J. Am. Chem. Soc. 2003, 125, 11784-11785; c) G. De Paëpe, A. Lesage, S. Steuernagel, L. Emsley, ChemPhysChem 2004, 5, 869875.

[3] D. A. Hall, D. C. Maus, G. J. Gerfen, S. J. Inati, L. R. Becerra, F. W Dahlquist, R. G. Griffin, Science 1997, 276, 930-932.

[4] V. S. Bajaj, C. T. Farrar, M. K. Hornstein, I. Mastovsky, J. Vieregg, J. Bryant, B. Elena, K. E. Kreischer, R. J. Temkin, R. G. Griffin, J. Magn. Reson. 2003, 160, 85-90.

[5] M. Rosay, L. Tometich, S. Pawsey, R. Bader, R. Schauwecker, M. Blank, P. M. Borchard, S. R. Cauffman, K. L. Felch, R. T. Weber, R. J. Temkin, R. G. Griffin, W. E. Maas, Phys. Chem. Chem. Phys. 2010, 12, 5850-5860.

[6] a) V. S. Bajaj, M. L. Mak-Jurkauskas, M. Belenky, J. Herzfeld, R. G. Griffin, Proc. Natl. Acad. Sci. U S A 2009, 106, 9244-9249; b) T Jacso, W. T. Franks, H. Rose, U. Fink, J. Broecker, S. Keller, H. Oschkinat, B. Reif, Angew. Chem. Int. Ed. 2012, 51, 432-435.

[7] a) M. L. Mak-Jurkauskas, V. S. Bajaj, M. K. Hornstein, M. Belenky, R. G. Griffin, J. Herzfeld, Proc. Natl. Acad. Sci. U S A 2008, 105, 883-888; b) A. H. Linden, S. Lange, W. T. Franks, U. Akbey, E. Specker, B. J. van Rossum, H. Oschkinat, J. Am. Chem. Soc. 2011, 133, 19266-19269.

[8] M. Renault, S. Pawsey, M. P. Bos, E. J. Koers, D. Nand, R. Tommassen-van Boxtel, M. Rosay, J. Tommassen, W. E. Maas, M. Baldus, Angew. Chem. Int. Ed. 2012, 51, 2998-3001.

[9] A. Lesage, M. Lelli, D. Gajan, M. A. Caporini, V. Vitzthum, P. Miéville, J. Alauzun, A. Roussey, C. Thieuleux, A. Mehdi, G. Bodenhausen, C. Copéret, L. Emsley, J. Am. Chem. Soc. 2010, 132, 15459-15461.

[10] O. Lafon, M. Rosay, F. Aussenac, X. Y. Lu, J. Trébosc, O. Cristini, C. Kinowski, N. Touati, H. Vezin, J. P. Amoureux, Angew. Chem. Int. Ed. 2011, 50, 8367-8370.

[11] V. Vitzthum, P. Miéville, D. Carnevale, M. A. Caporini, D. Gajan, C. Copéret, M. Lelli, A. Zagdoun, A. J. Rossini, A. Lesage, L. Emsley, G. Bodenhausen, Chem. Commun. 2012, 48, 1988-1990.

[12] Part of this research was presented at the COST meeting, Dublin Ireland, 29 June - 1 July 2012. 2D refocused INADEQUATE experiments on NA glucose using DNP recorded in 16 hours were also presented by Emsley and co-workers at the 8th EUROMAR, Dublin, Ireland, 1 - 5 July 2012.

[13] U. Akbey, W. T. Franks, A. Linden, S. Lange, R. G. Griffin, B. J. van Rossum, H. Oschkinat, Angew. Chem. Int. Ed. 2010, 49, 7803-7806. 
[14] a) A. J. Rossini, A. Zagdoun, M. Lelli, D. Gajan, F. Rascon, M. Rosay, W. E. Maas, C. Copéret, A. Lesage, L. Emsley, Chem. Sci. 2012, 3, 108-115; b) A. J. Rossini, A. Zagdoun, M. Lelli, J. Canivet, S. Aguado, O. Ouari, P. Tordo, M. Rosay, W. E. Maas, C. Copéret, D. Farrusseng, L. Emsley, A. Lesage, Angew. Chem. Int. Ed. 2012, 51, 123-127.

[15] V. Vitzthum, F. Borcard, S. Jannin, M. Morin, P. Mieville, M. A. Caporini, A. Sienkiewicz, S. Gerber-Lemaire, G. Bodenhausen, ChemPhysChem 2011, 12, 2929-2923.

[16] C. Song, K. N. Hu, C. G. Joo, T. M. Swager, R. G. Griffin, J. Am. Chem. Soc. 2006, 128, 11385-11390.
[17] A. H. Linden, W. T. Franks, U. Akbey, S. Lange, B. J. van Rossum, H. Oschkinat, J. Biomol. NMR 2011, 51, 283-292.

[18] M. Hohwy, H. J. Jakobsen, M. Edén, M. H. Levitt, N. C. Nielsen, J. Chem. Phys. 1998, 108, 2686-2694.

[19] K. Takegoshi, S. Nakamura, T. Terao, Chem. Phys. Lett. 2001, 344, 631-637. 
Layout 2:

\section{D ${ }^{13} \mathrm{C}-{ }^{13} \mathrm{C}$ NMR at natural}

abundance.

Hiroki Takahashi, Daniel Lee, Lionel

Dubois, Michel Bardet, Sabine Hediger,

Gaël De Paëpe*

Page -

Page

20 Minute Natural Abundance $2 \mathrm{D}{ }^{13} \mathrm{C}-$

${ }^{13} \mathrm{C}$ Correlation Spectroscopy Using

DNP-Enhanced Solid-State NMR and

Matrix-Free Sample Preparation

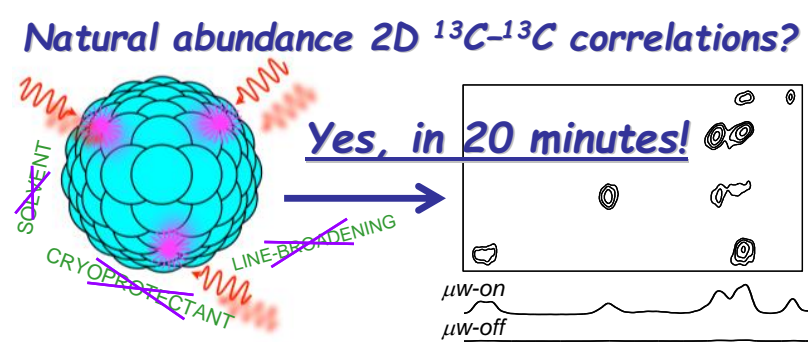

Substantial solid-state NMR sensitivity can be achieved using dynamic nuclear polarization and Matrix-Free sample preparation allowing very fast natural abundance 2D ${ }^{13} \mathrm{C}-{ }^{13} \mathrm{C}$ dipolar correlation experiments. 